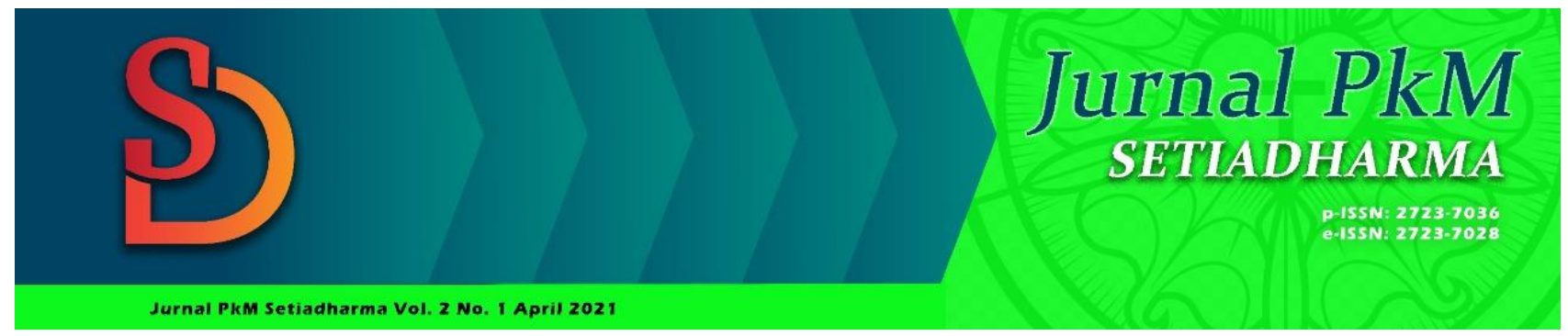

\title{
GEREJA MEMPERSIAPKAN PEMUDA MELALUI MENTORING DI GBI ASIA AFRIKA BANDUNG
}

\author{
Robert William ${ }^{1}$, Yanto Paulus Hermanto ${ }^{2}$, Joko Prihanto ${ }^{3}$ \\ robertrungkat@gmail.com, yantopaulush@gmail.com, tugasjokopri@gmail.com
}

\begin{abstract}
Diterima:
09-12-2020

Direview:

21-12-2020

15-03-2021

Direvisi:

27-12-2020

29-03-2021

Diterbitkan:

30-04-2021

\section{Abstract}

With the progress of the changing times, making all things in this world experience significant changes, even the church did not escape from these challenges. But the most striking problem in the end times is the lack of the church to prepare the younger generation or youth for the future. Because the younger generation is the future of the church. The church forgetting the younger generation is the same as forgetting the future of the church itself. Therefore, the author here is interested in further researching how the church prepares itself for the future by mentoring youth so that the church has a bright future and is maintained according to God's will? And what the author has researched, is practiced in the Bethel Church of Indonesia Asia Africa (Kalam Hidup) Bandung to prove whether youth mentoring can answer previous questions at GBI Asia Afrika (Kalam Hidup) Bandung?

Keywords: Church, youth, mentoring, role model, Mentor Responsibility

Kata Kunci: Gereja, pemuda, mentoring, teladan, tanggung jawab mentor

\section{Abstrak}

Dengan adanya kemajuan zaman yang berubah demikian majunya, membuat semua hal di dunia ini mengalami perubahan signifikan, gereja sekalipun tidak luput dari tantangan tersebut. Tapi masalah mencolok yang terberat di akhir zaman ini adalah kurangnya gereja mempersiapkan generasi muda atau pemuda untuk menghadapi masa depan. Karena generasi muda adalah masa depan gereja. Gereja melupakan generasi muda sama dengan melupakan masa depan gereja itu sendiri. Oleh sebab itu penulis disini tertarik untuk meneliti lebih jauh tentang bagaimana gereja mempersiapkan diri buat masa yang akan datang dengan mementori pemuda maka gereja mempunyai masa depan yang cerah dan terjaga sesuai kehendak Tuhan? Dan apa yang diteliti penulis, dipraktikan di dalam Gereja Bethel Indonesia Asia Afrika (Kalam Hidup) Bandung untuk membuktikan, apakah dengan mentoring pemuda bisa menjawab pertanyaan sebelumnya di GBI Asia Afrika (Kalam Hidup) Bandung?
\end{abstract}

\footnotetext{
${ }^{1}$ Prodi Teologi Sekolah Tinggi Teologi Kharisma Bandung ${ }^{2}$ Prodi Teologi Sekolah Tinggi Teologi Kharisma Bandung ${ }^{3}$ Prodi Teologi Sekolah Tinggi Teologi Kharisma Bandung
} 


\section{PENDAHULUAN}

Seiring dengan majunya perkembangan zaman diikuti dengan perubahan yang sangat cepat dengan adanya teknologi yang semakin berkembang, membuat semua hal di dunia ini mengalami perubahan signifikan. Gereja pun tidak luput dari tantangan karena hal itu, tapi salah satu tantangan terberat di akhir zaman bagi gereja saat ini adalah kurangnya regenerasi. Sahartian menjelaskan bahwa gereja umumnya kurang membuka kesempatan agar pemuda dapat memperluas potensinya dalam membangun gereja, keraguan gereja terhadap keterlibatan pemuda ini terlihat jelas dikarenakan kehidupan pemuda Kristen itu sendiri, yang dianggap kurang mampu, akibatnya gereja tidak dapat memberikan tanggung jawab yang besar kepada pemuda. Selain karena kehidupan pemuda Kristen dirasa menjauh dari firman Tuhan, juga karena faktor usia yang relatif muda. ${ }^{4}$

Myron Rush mengatakan, "Masyarakat saat ini telah mengeluhkan adanya kekurangan pemimpin dalam jajarannya, dalam tahun-tahun belakangan ini keluhan itu berubah menjadi suatu seruan yang meresahkan. Kekurangan pemimpin dalam masyarakat Kristen telah mendatangkan korban yang mengkhawatirkan. Banyak aliran gereja besar yang dahulunya kuat dan berkembang sekarang mengalami kemerosotan yang tajam dalam jumlah keanggotaannya. Beberapa aliran gereja terpaksa menutup pintu gerejanya karena tidak tersedia cukup banyak gembala jemaat yang dapat melayani." 5 Kekurangan pemimpin dalam gereja telah mendatangkan masalah bagi kekristenan, yaitu menurunnya kualitas rohani dan jumlah jemaat, sehingga gereja yang berkembang tidak mengalami kemajuan. Oleh sebab itulah gereja juga harus fokus untuk membina generasi muda (regenerasi). Gereja melupakan generasi muda artinya menutup masa depan gereja itu sendiri. ${ }^{6}$ Generasi muda dewasa ini sangat jauh berbeda dengan generasi sebelumnya, karena generasi muda saat ini sangat ditopang oleh kemajuan zaman yang sangat cepat. Seperti teknologi yang canggih, individualistis tinggi, kemajuan dunia pendidikan, musik rock and roll, tekanan dari sesama, gaya hidup bebas ala barat, dan ini sangat berpengaruh negatif terhadap kepemimpinan generasi masa kini. Maxwell berpendapat: "Sementara saya berkeliling seluruh penjuru negara setiap akhir pekannya, berbicara dengan ribuan anak muda-mudi, saya selalu melihat efekefek sebuah generasi yang telah dipimpin oleh rock and roll, tekanan sesama, dan oleh orang yang tidak memiliki landasan yang mantap dalam Allah. ${ }^{7}$ Akibatnya terbentuklah memiliki generasi muda yang jatuh ke dalam dosa, seks bebas, narkoba, anarkis, tawuran, bullying dan kenakalan anak muda lainnya.

Menghilangnya keberadaan pemuda di dalam jemaat terjadi melalui berbagai macam faktor, salah satu faktornya adalah pemuda yang merasa bahwa gereja tidak memberikan jawaban-jawaban atas pertanyaan yang mereka ajukan dengan jujur dan kritis. ${ }^{8}$ Rasa tidak puas inilah yang membuat pemuda memilih untuk mencari tempat lain yang dirasa dapat lebih menjawab kebutuhan-kebutuhan mereka. Salah satu contoh, perkembangan statistik pelayanan generasi muda di Korea Selatan belum lama ini menunjukkan kekristenan

\footnotetext{
4 Santy Sahartian, "Tugas Pemimpin Muda Kristen Masa Kini Sebagai Gembala Menurut 1 Timotius 4," Angelion: Jurnal Teologi dan Pendidikan Kristen 1, no. $1 \quad$ (2020): 83-97, https://ejournal.sttberitahidup.ac.id/index.php/jan/article/view/45/42.

${ }^{5}$ Myles Munroe, The Spirit Leadership, The Spirit. (Jakarta: Immanuel, 2002), 13.

${ }^{6}$ Berlin Sinulingga and Yunus D A Laukapitang, "Kajian Pengajaran PAK Terhadap Motivasi Beribadah Pemuda Di GBI MCC Makassar," Repository Skripsi Online 1, no. 3 (2019): 191-197, https://skripsi.sttjaffray.ac.id/index.php/skripsi/article/view/49.

7 John C. Maxwell, Leading From The Lockers, ed. interaksa (batam: Interaksa, 2001).

${ }^{8}$ David Kinnaman, You Lost Me (USA: Baker Books, 2012), 11.
} 
mengalami penurunan. Anak-anak muda berkisar 15-20 tahun meninggalkan gereja dan hanya sekitar 2,9\% dari mereka yang mau mengakui diri sebagai pengikut Kristus. ${ }^{9}$ Sedangkan di Indonesia sendiri Bilangan Research Center mengadakan survei pada 4095 anak remaja di Indonesia pada tahun 2017, rata-rata anak remaja yang mengikuti ibadah 4 kali dalam 3 bulan sebesar 63,8\% sedangkan sisanya hanya 2 atau 3 kali ibadah. Hal ini tentu menjadi pertimbangan yang sangat mendesak bagi gereja, karena jika dibiarkan maka semakin lama gereja akan semakin kosong. ${ }^{10}$

Dari penjelasan di atas, dapat disimpulkan sementara bahwa pentingnya gereja mempersiapkan generasi muda saat ini untuk hasil di masa yang akan datang. Jika tidak, maka akan terjadi kemunduran signifikan dalam gereja di masa yang akan datang. Oleh sebab itu penulis ingin meneliti lebih jauh tentang "gereja mempersiapkan generasi muda melalui mentoring." Melalui pendekatan mentoring kita bisa melihat hasilnya di dalam Alkitab, bagaimana Yosua mampu menaklukan tanah Kanaan, Elisa mempunyai pengurapan ganda, Timotius menggembalakan jemaat yang besar dan Tuhan Yesus Kristus berhasil mementor murid-murid-Nya. ${ }^{11}$

\section{METODE PELAKSANAAN}

Penulis memilih metode penelitian deskriptif yang digunakan untuk menjelaskan kenyataan dari sebuah realita. Jenis penelitian yang memberikan gambaran atas suatu keadaan sejelas mungkin tanpa ada perlakuan terhadap objek yang diteliti. Juga penulis menggunakan penelitian kualitatif, karena penulisan jurnal ini berupa penelitian data nonstatistik. Teknik pengumpulan data ini adalah hal yang sangat penting menurut penulis. Dalam arti hasil penelitian akan lebih akurat, jika data yang diperoleh memadai sehingga memberikan informasi yang lengkap. Untuk mencapai hasil yang baik, yaitu berupa data yang valid dan akurat dalam penulisan jurnal ini, maka penulis mempergunakan studi kepustakaan. Proses yang dikerjakan pada pelaksanaan mentoring ini adalah sebagai berikut: permintaan izin kepada Bapak Gembala dan melakukan mentoring kepada pemuda/remaja GBI Asia Afrika Bandung.

\section{HASIL DAN PEMBAHASAN}

Hal yang dilakukan dalam kegiatan pengabdian ini, melalui mentoring dengan rentang waktu selama 3 bulan, kemudian setelah mendapatkan izin kepada Gembala, maka dimulai dari 12 Januari - 29 Maret 2020, pertemuan diadakan di GBI Asia Afrika Bandung, setiap 1 minggu sekali pukul 09:30-10:30. Adapun materi yang dibagikan dalam kegiatan tersebut ialah tentang takut akan Allah, menghormati orang tua, dan cara menjaga pergaulan sesuai firman Tuhan serta simulasi sederhana mempresentasikan setiap materi yang telah dibagikan pada setiap akhir bulan.

${ }^{9}$ COO CBN Indonesia, "Kita Sedang Kehilangan Satu Generasi,” last modified 2015, accessed November 28, 2020, www.jawaban.com.

${ }^{10}$ Superbook Indonesia, "Fakta Yang Menyebabkan Anak Muda Meninggalkan Gereja , Apakah Gereja Mau Berdiam Diri Saja," accessed November 28, 2020, www.superbookIndonesia.com/article/read/584.

11 Agus Prihanto, "Peran Proses Mentoring Pemimpin Kaum Muda Bagi Perkembangan Pelayanan Pemuda Di Gereja," Jurnal Jaffray 16, no. 2 (October 6, 2018): 197. 


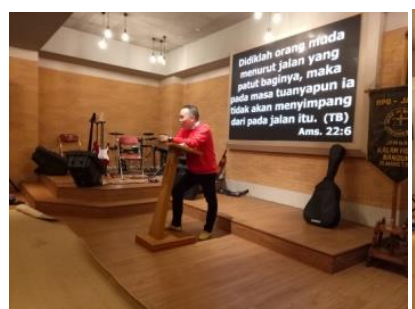

Gambar. 1

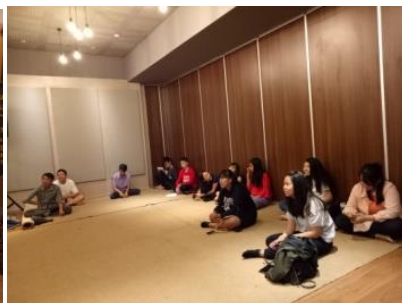

Gambar. 2

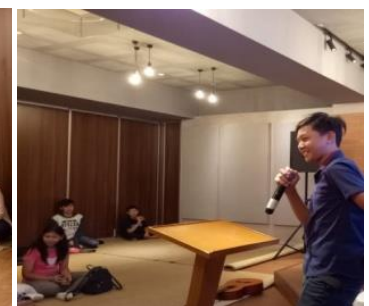

Gambar. 3

Gambar 1 menerangkan peneliti memulai pertemuan mentoring dengan penjelasan materi awal, gambar 2 menunjukkan para peserta atau mentee, dan gambar ke 3 adalah simulasi.

\section{Mentoring}

Kata mentoring berasal dari kata mentor yang diterjemahkan pembimbing atau pengasuh. Caffarella mendeskripsikan: "Mentoring is intensif, caring relationship in which someone with experience works with a less experienced person to promote both professional growths. ${ }^{12}$ Artinya mentoring adalah suatu hubungan yang dalam di mana pribadi yang mempunyai pengalaman bekerja dengan pribadi yang tidak berpengalaman supaya membantu atau mengangkatkan orang yang kurang berpengalaman baik dalam profesional maupun dalam perkembangan pribadi. Sederhananya mentoring ialah peristiwa seseorang menolong orang lain untuk mendalami sesuatu, tidak menutup hidupnya kepada orang lain, mensharingkan kehidupannya dengan orang lain, supaya membentuk sebuah proses di mana seseorang hidup untuk melahirkan generasi yang yang ada di depan. Mentoring sangat berhubungan erat dengan kepemimpinan (leadership) di mana seseorang (mentor) mempunyai kemauan dalam mengarahkan atau melatih serta memimpin orang lain (mentee) supaya pribadi yang dibimbing dan diarahkannya di hari depan sanggup menjadi sepenuhnya dalam segala aspek kehidupannya.

Pemuda membutuhkan sosok yang dilihat memiliki teladan perkataan, dalam tingkah laku, dalam kasih, dalam kesetiaan dan dalam kesucian, sebab ketika mereka tidak menemukan keteladanan tersebut di rumah misalnya atau orang tua, dan juga tidak menemukan orang lain yang pantas diteladani dalam lingkungan sekitar, akibatnya mereka terus mencari orang yang dapat menjadi teladan bagi kehidupan mereka sampai. Gerejalah yang harus menjawab keperluan ini dengan menghadirkan mentor-mentor yang menjadi teladan kepada anak-anak muda.

\section{Menjadi Teladan}

Seorang pemimpin anak muda dapat menjadi teladan bagi orang lain, khususnya orangorang yang dimentornya, sekalipun ia masih muda. Hal ini juga yang disampaikan oleh Paulus kepada Timotius di dalam 1 Timotius 4:12 dikatakan, "Jangan seorangpun menganggap engkau rendah karena engkau muda. Jadilah teladan bagi orang-orang percaya, dalam

12 Rosemary S. Cafferella, Planning Programs for Adult Learners: A Practical Guide for Educators, Trainers and Staff Developers (San Fransisco: Jossey-Bass Publishers, 1994). 
perkataanmu, dalam tingkah lakumu, dalam kasihmu, dalam kesetiaanmu dan dalam kesucianmu.

\section{Membimbing}

Dalam Kisah Para Rasul 8:30-31 saat Filipus bertemu dengan sida-sida Etiopia yang sedang membaca kitab nabi Yesaya: Filipus segera ke situ dan mendengar sida-sida itu sedang membaca kitab nabi Yesaya. Kata Filipus: "Mengertikah tuan apa yang tuan baca itu? Jawabnya: 'Bagaimanakah aku dapat mengerti, kalau tidak ada yang membimbing aku?'” Lalu ia meminta Filipus naik dan duduk di sampingnya. Sida-sida mengatakan satu hal yang ia butuhkan yaitu bimbingan. Bimbingan untuk mengerti firman Tuhan. Jarot Wijanarko menuliskan dalam buku Father and Son bahwa mentor adalah seorang yang lebih dewasa, yang secara nyata membimbing, baik dalam kehidupan sehari-hari maupun dalam hal rohani. ${ }^{13}$ Howard G Hedricks mengungkap bahwa sebagai pembimbing yang efektif , tidak hanya isi pengajaran atau hal apa yang harus diajarkan kepada pemuda lebih lagi harus mengenal siapa yang akan diajar. Dalam hal ini gereja harus mengerti keduanya yaitu materi firman yang harus diajarkan serta keseharian atau kehidupan para pemuda yang akan dibimbing.

Dampak dari mentoring di bulan Juni 2020, anak-anak muda yang mengikuti kegiatan tersebut, yaitu: secara konsisten membaca setiap hari minimal 2 pasal, nilai pendidikan di sekolah semua baik, sebagian besar juara di sekolah, semua menghormati orang tua, menjadi terlibat dalam pelayanan kaum muda, dan dalam pergaulan terjaga dengan baik, tidak ada yang merokok, terlibat pornografi atau seks bebas, narkoba dan kenakalan remaja/pemuda lainnya. Salah satu dampak paling signifikan adalah mereka memutuskan untuk menyerahkan hidup kepada Tuhan lewat baptisan (gambar 4 mereka memutuskan untuk dibaptis, gambar 5-6 penyerahan surat baptisan). Dari sini terlihat bahwa proses mentoring sangat menunjang gereja untuk mempersiapkan generasi muda.

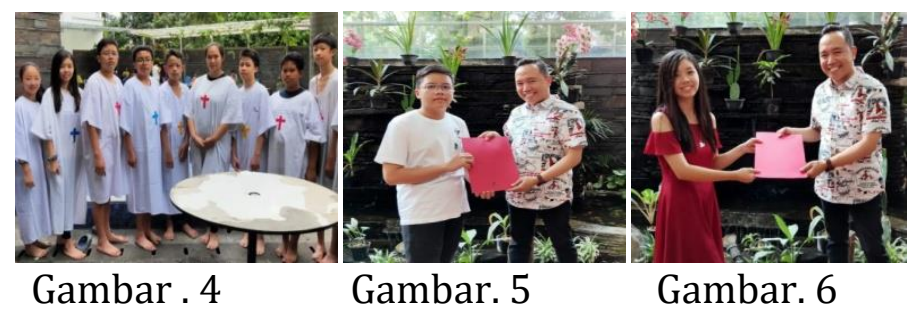

\section{KESIMPULAN}

Dari penjelasan di atas, penulis menarik kesimpulan bahwa gereja saat ini sudah seharusnya fokus dan menaruh porsi yang sangat besar untuk memperhatikan kaum muda, karena merekalah yang akan menentukan kemajuan gereja di masa yang akan datang. Dengan mengambil bagian penuh untuk mengambil tanggung jawab, menjadi teladan baik dalam

\footnotetext{
${ }^{13}$ Jarot Wijanarko, Father and Son (Jakarta: Keluarga Indonesia Bahagia, 2016), 35.
} 
perkataan, tingkah laku, kesucian, kesetiaan, dan kasih, bagi anak-anak muda agar mereka mendapatkan jawaban persoalan, tantangan dalam kehidupan, juga supaya mereka tidak terhilang melainkan menjadi dampak buat keluarga, gereja, masyarakat dan bangsa. Anak muda terhilang, gereja akan hilang di masa depan, gereja jadi jawaban bagi anak muda dengan menjadi mentor, maka gereja akan kuat dan terus maju di masa sekarang dan di masa yang akan datang. Peneliti juga sudah melihat dan merasakan langsung bagaimana dampak mentoring buat kaum muda di gereja, selain menunjang kerohanian mereka, mendukung dalam hal studi menjadi lebih baik dan bertanggung jawab, terjaga dalam pergaulan dalam pengaruh buruk kemajuan zaman, serta membanggakan orangtua dan tentunya memuliakan Tuhan lewat hidup mereka. Penulis meyakini generasi muda seperti inilah yang dibutuhkan gereja untuk menjawab setiap tantangan zaman, menjadi semakin berdampak dan nyata kasih Kristus, baik masa kini sampai masa depan.

\section{DAFTAR PUSTAKA}

Indonesia, C. C. (2015). Kita Sedang Kehilangan Satu Generasi. www.jawaban.com

Indonesia, S. (n.d.). Fakta Yang Menyebabkan Anak Muda Meninggalkan Gereja, Apakah Gereja Mau Berdiam Diri Saja. Retrieved November 28, 2020, from www.superbookIndonesia.com/article/read/584

John C. Maxwell. (2001). Leading From The Lockers (interaksa (ed.)). Interaksa.

Kinnaman, D. (2012). You Lost ME. Baker Books.

Munroe, M. (2002). The Spirit Leadership (The Spirit). Immanuel.

Prihanto, A. (2018). Peran Proses Mentoring Pemimpin Kaum Muda Bagi Perkembangan Pelayanan Pemuda Di Gereja. Jurnal Jaffray, 16(2), 197. https://doi.org/10.25278/jj71.v16i2.258

Rosemary S. Cafferella. (1994). Planning Programs for Adult Learners: A Practical Guide for Educators, Trainers and Staff Developers. Jossey-Bass Publishers.

Sahartian, S. (2020). Tugas Pemimpin Muda Kristen Masa Kini Sebagai Gembala Menurut 1 Timotius 4. Angelion: Jurnal Teologi Dan Pendidikan Kristen, 1(1), 83-97. https://ejournal.sttberitahidup.ac.id/index.php/jan/article/view/45/42

Sinulingga, B., \& Laukapitang, Y. D. A. (2019). Kajian Pengajaran PAK Terhadap Motivasi Beribadah Pemuda Di GBI MCC Makassar. Repository Skripsi Online, 1(3), 191-197. https://skripsi.sttjaffray.ac.id/index.php/skripsi/article/view/49

Unarto, E. (2006). Bertumbuh Dalam Karakter Baru (4th ed.). Pustaka Sorgawi.

Wijanarko, J. (2016). Father and Son. Keluarga Indonesia Bahagia. 